\title{
Impact of Domestic Waste Exposure on Health and Nutritional Status of Children Aged 5-7 Years
}

\section{Awan $\mathbf{R}^{1^{*}}$, Khan $\mathbf{N}^{2}$ and Nasir $\mathbf{M}^{2}$}

${ }^{1}$ Department of Food Sciences and Human Nutrition, Kinnaird College for Women, Lahore, Pakistan

${ }^{2}$ Kinnaird College for Women, Lahore, Pakistan

"Corresponding author: Awan R, Department of Food Sciences and Human Nutrition, Kinnaird College for Women, Lahore, Pakistan, Tel: 03316362963; E-mail: mdyawan@yahoo.com

Received date: Nov 18, 2016; Accepted date: Dec 05, 2016; Published date: Dec 12, 2016

Copyright: (c) 2016 Awan R, et al. This is an open-access article distributed under the terms of the Creative Commons Attribution License, which permits unrestricted use, distribution, and reproduction in any medium, provided the original author and source are credited.

\begin{abstract}
Environment and health are interrelated suggesting any change in one will effect and alter the other. Domestic solid waste dump exposure exerts harmful impact on health of humans especially children. Children (age group 5-7 years) were compared with a group of children having similar socio-economic background but not exposed to waste dumps. The results showed that the weight $(M=15.8 \mathrm{~kg}$ with $S D \pm 5.6)$, height $(M=41.4$ inches with $S D \pm 3.7)$ and BMI $\left(M=14.1 \mathrm{~kg} \cdot \mathrm{m}^{2}\right.$ with $\left.\mathrm{SD} \pm 3.3\right)$ of observational children were below the values of those not exposed and also below recommended values. Additionally, they exhibited the clinical symptoms of iron, calcium and protein deficiencies seen in their pale eyes, nails and skin, discoloured teeth and brittle hair. Overall disease status in both groups was almost similar. Waste exposed children were suffering more from diarrhoea as compared to others. Other health related problems like eyes infection, skin infections/allergies, respiratory tract infections and nervous disorders were also prevalent among waste dump dwelling children. The results of CDC percentile growth charts depicted that waste-exposed children scored lower for weight-for-age $(30 \%)$ sample exhibited $3^{\text {rd }}-5^{\text {th }}$ percentile scores) and BMI-for-age growth charts (25\% sample exhibited below 5 th percentile scores), whereas height-for-age growth charts showed no discrete results. Hence, it has been proved that compromised health and nutritional status was observed among waste exposed children by reporting malnutrition and wasting in them.
\end{abstract}

Keywords: Domestic waste; Waste exposure; Health status; Nutritional status

\section{Introduction}

Improper disposal of domestic waste in urban settings is a huge threat to environment and health, as well as, growth and development of citizens. According to United Nations Environment Programs, environment has a direct impact on the human health and nutritional status. Polluted environment, on one hand, originates ecosystem degradation which causes less food production and ultimately food insecurity and malnutrition, resulting in compromised health status. On the other hand, polluted environment produces health sufferings including infections, toxicities, allergies and disorders, resulting in compromised nutritional status [1].

Several epidemiological studies have shown an increased risk of health and nutritional problems among population living close to open domestic waste dumping sites. These problems mainly include gastrointestinal, hepatic, renal and reproduction disorders, and growth retardation [2]. Their short-term effects include dermal pathogenicities, congenital anomalies, respiratory infections and underweight; whereas long-term effects include chronic respiratory and cardiovascular diseases, cancer, cerebroneural abnormalities, stunting and wasting [3].

In Kenya, a UNEP report found that municipal waste dumpsites contain heavy metals and persistent organic pollutants which are inhaled, ingested and absorbed resulting in skin, respiratory, abdominal, intestinal, dental, ear, skeletal muscular, central nervous, eyes and blood disorders in children [4]. In Senegal, a poor western
African country, a multiple-purposive research was conducted to study the impact of solid urban waste exposure to esthetics and human health. It expounded that waste dumpsites are source of water and air pollution which ultimately turns into health hazards like respiratory tract abnormalities and several toxicities inside body [5].

One of the studies conducted to assess the same effect on children's growth between $0-3$ years of age in Colombia revealed that exposure to such site was found associated with decreased WHO growth indices of children [6]. A relevant case controlled study, conducted to evaluate the environmental influence on growth pattern of children living along Love Canal (USA), demonstrated that the exposed children had shorter stature, several types of mutational disorders and many other developmental abnormalities as compare to the unexposed ones [7].

\section{Materials and Methods}

\section{Participants}

In the study, two different groups of individuals were analysed for same variables. Group A was comprised of individuals exposed to domestic wastes dumpsites, and group B had individuals with same socio-economic status but not exposed to waste. Total sample size was 100 with equal representation of both genders. Sample assignment for both groups was done in two levels: 1 ) four vicinities were selected in Lahore, 2 for group A and 2 for group B as per researchers' ease; due to certain security issues access to all required vicinities was not possible; 2) balanced assignment of subjects was done for both groups. The sample for group A included all subjects found at the selected vicinities falling under inclusion and exclusion criteria $(\mathrm{nA}=50)$. A comparable 
proportionate number of samples were included in group B for a counter check $(\mathrm{nB}=50)$.

Inclusion criteria: Age of 5, 6 and 7 years; both genders males and females; resident of an underprivileged area by birth; parental educational level below or equivalent to primary; parental employment status either unemployed or linked to occupations like labour, hawker and housemaid; Punjabi race; and absence of diarrhoea, stomach-ache and vomiting at the time of examination. For group A, the selection criteria also included the exposure of domestic waste dumps to the subject more than 12 hours a day [8].

Exclusion criteria: being parental orphan; disabled [9]; injured [10]; stayed for 2 months or more unexposed to waste immediately prior to examination (for observational group); and unwilling to participate.

\section{Design}

The present study was an observational study to explore the effect of waste exposure on nutritional status. Here, the independent variable was waste exposure and dependent variable was nutritional status. For this purpose, two groups were designed ascribing similar traits except waste dump exposure. As the waste exposure was pre-existing, so no manipulation was formulated in either of the two groups.

\section{Procedure}

Initially, the vicinities were selected and the visits were made, to collect data, on the basis of access availability. Before this, a permission letter was obtained by the College administration and consent was obtained by the authorities of these areas. Also, verbal consent was taken from each sample (family) before making him/her a part of study during door-to-door visiting method. The data collection continued over a time period of four months from October 2015 till January 2016. Most of the visits were made during evening hours ( 4 pm-7 pm), because mostly children and their mothers were at home (almost $80 \%$ ). Group A data was obtained from Mehmood Butti, the largest solid waste dumping and management site in Lahore, and there exist slums' dwellers over these dumping lands. While group B data was collected from four adjacent under-privileged localities in Lahore namely Makkah colony, Madina colony, Railway colony and Peer colony (Walton). After the completion of data collection, data analysis was carried out. Results of both groups were compared.

\section{Instrumentation}

The predominant data of research comprised of nutritional status of subjects. To assess nutritional status, CDC weight-for-age, stature-forage and body mass index-for-age percentile growth charts were used. Other variables checked for health and nutritional status were physical signs and symptoms [11] including eyes, nails, teeth, hair and skin examination; stool character and pattern; current eye, skin or respiratory allergy/infection or nervous disorder; and frequency of severe sickness [12,13]. Besides this, the socio-demographic data was also collected to check the sample on inclusion and exclusion criteria. Other instruments used to collect anthropometric data, i.e., for height and weight were standing height measuring scale with a precision of $0.1 \mathrm{~cm}$, and an analogue weighing machine with a precision of $0.1 \mathrm{lbs}$.

Meanwhile, a data form was developed and tested for validity and reliability with the help of a pilot study including 10 samples. It was declared valid by three experts of the field and reliable with a test-retest reliability test score Pearson's $r=0.88$.

\section{Statistical analysis}

The descriptive statistical methods used were mean and standard deviation whereas inferential statistical methods used was independent sample $t$-test and Mann-Whitney $U$ test. These results were demonstrated in the form of figures e.g., bar diagram, line graphs and pie charts. The software used to analyse data was SPSS version 21.0 (SPSS Inc.).

\section{Results}

\section{Participants characteristics}

For both groups, sample included 5 years aged (36\%), 6 years aged (32\%) and 7 years aged (30\%) children with 50\% representation from each gender. The dissemination of age among the two groups was checked using Mann-Whitney $U$ test. Its result accepted null hypothesis with significance value $1.00(\mathrm{p}=0.05)$ stating that the distribution of age was the same across the two groups (Figure 1).

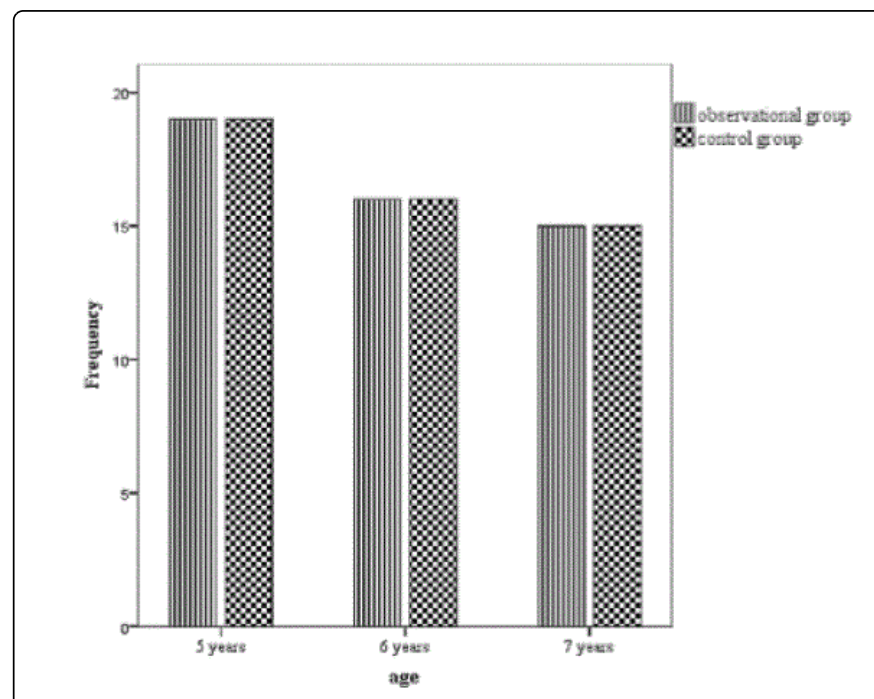

Figure 1: Bar diagram showing frequencies distribution for age of participants in both groups.

Furthermore, the socio-demographic results included parental literacy level i.e., below primary education were $82.3 \%$ and $74.2 \%$ in group A and B respectively, which is very low as compared to $44.5 \%$ Kolkata's slum dwellers with educational level below primary [14]. Recently, it has found that $78 \%$ slums were literate in India whereas overall $44.7 \%$ population in Pakistan is literate $[15,16]$.

Moving on towards employment status, results revealed that most of the fathers in either group were unemployed, $63 \%$ in group A. Contrarily, $74 \%$ mothers were employed in group A (Figure 2). As men were not earning, so women were mainly the bread earners for their families. In addition to lack of economic amenities, the mothers did not have enough time and energy to feed, raise and take care of their children well due to their occupational load. This provides an evidence of compromised health and nutritional conditions of women and children in these slums. 

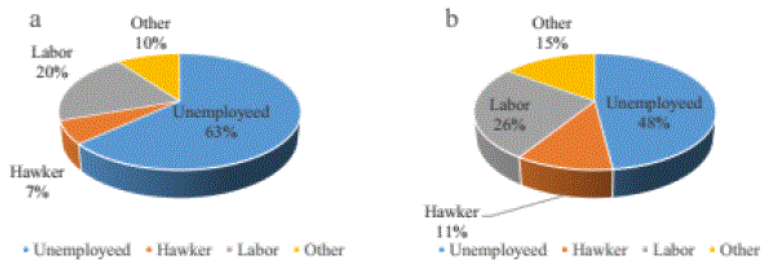

Figure 2a: Pie charts showing father's employment status a) in observational group; b) in control group.
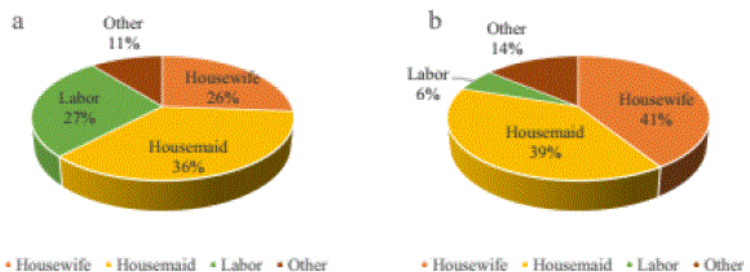

Figure 2b: Pie charts showing mother's employment status a) in observational group; b) in control group.

In the meanwhile, the numbers of siblings of subjects were averaged on 5-6 siblings in group A and 3-4 siblings in group B. Also the frequency of subjects with more than 6 siblings was eight times higher in group A (Figure 3). In addition, the mothers in waste-exposed group were younger than that in waste unexposed group (Figure 4), which also contributes in compromised nutritional and health status of children. This is because of manifold reasons including lack of education, early marriages, lack of maternal and infant health facilities and awareness, religious myths and certain social pressures thus population in slums is on the rise [17]. People believe that having more children is for a better future as these children will become earning hands later on, but their breeding and raising cost is always underestimated; this is where problems do generate.

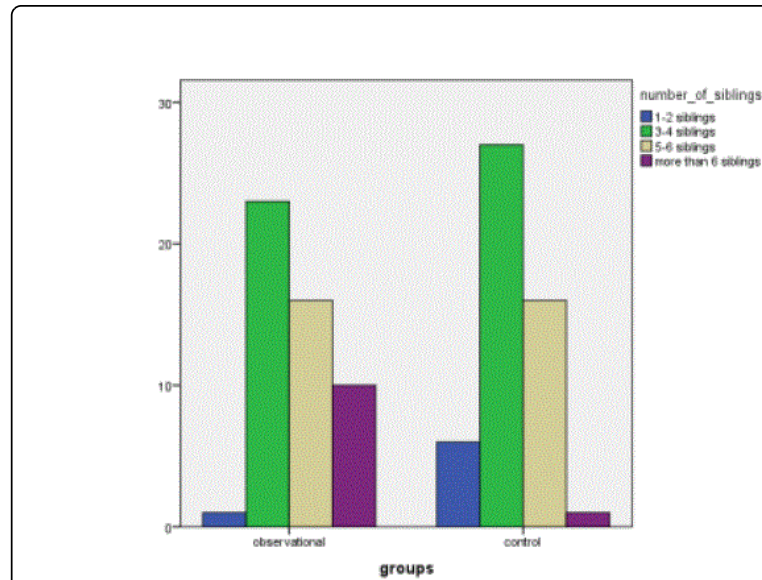

Figure 3: Bar Diagram showing comparison of number of siblings for both groups.

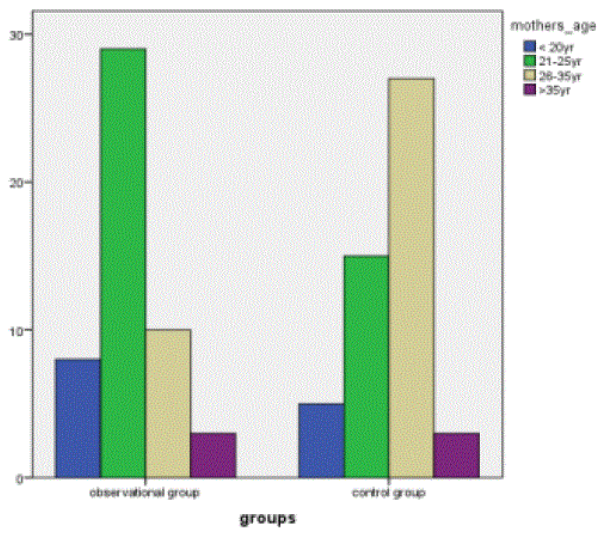

Figure 4: Bar diagram showing comparison of mother's age for both groups.

\section{Anthropometrics results}

A significant difference was observed between the weights, heights and BMI of both groups. For weights, the mean weight in group A was $16 \mathrm{~kg}$ (SD 5.6) while that in group B was $22.5 \mathrm{~kg}$ (SD 2.0) where independent sample $t$-test results were $t(99)=-14.5, p=0.000$ (Figure 5). Similarly, the mean height of group A was 41 inches (SD 3.7) while that of group B was 43 inches (SD 2.4) where independent sample t-test results were $\mathrm{t}(99)=-2.62, \mathrm{p}=0.010$ (Figure 6). Likewise trend was observed in mean BMI values where group A averaged at $14 \mathrm{~kg} / \mathrm{m}^{2}$ (SD 3.3) and group B at $19 \mathrm{~kg} / \mathrm{m}^{2}$ (SD 2.1) where independent sample $\mathrm{t}$-test results were $\mathrm{t}(99)=-5.06, \mathrm{p}=0.000$ (Figure 7). Previously, no parallel research comparing weight, height and BMI of waste-exposed and unexposed children has been done so far. 
Citation: Awan R, Khan N, Nasir M (2016) Impact of Domestic Waste Exposure on Health and Nutritional Status of Children Aged 5-7 Years. Vitam Miner 5: 148.

Page 4 of 9

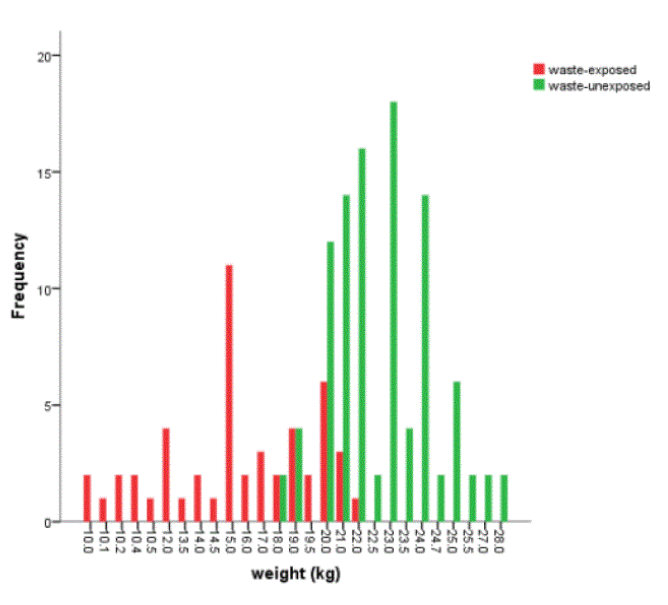

Figure 5: Bar diagram showing weight $(\mathrm{Kg})$ of participants in both groups.

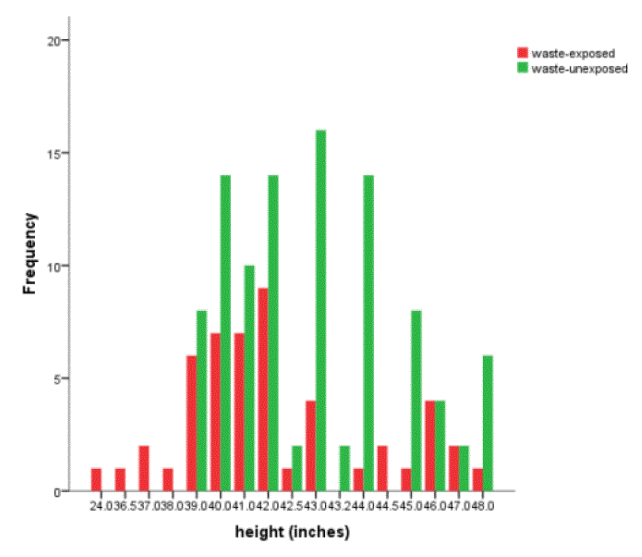

Figure 6: Bar diagram showing height (inches) of participants in both groups.

Here, Mann-Whitney U test was applied to check difference between anthropometrics of genders within the group. The result accepts null hypothesis with significance value $0.738(\mathrm{p}=0.05)$ for weight and 0.665 ( $\mathrm{p}=0.05)$ for height declaring that the anthropometric measurements are persistent among the genders.

Clinical Signs Examination: The clinical signs included the examination of eyes, nail, teeth, hair and skin for their colour, form, texture and some specific pathological signs.

Eyes: It was found that in group A, pale eyes were most prevalent i.e., $59 \%$, whereas white (normal) and reddish (infected) eyes were also observed in about $20-20 \%$ subjects. Also, four subjects were found with accidently injured eyes. In group B, the white eyes (normal) were most dominant with a frequency of $90 \%$. Other abnormal conditioned eyes were found with even less than $10 \%$ of sample (Figure 8 ). Nutritionally, pale eyes depict iron, vitamin B12, folate and protein deficiency [18].

Nails: In group A, $60 \%$ had pale nails, $30 \%$ had spooned and $8 \%$ had spotted nails, while only $2 \%$ had normal white/pink nails. In group B, $76 \%$ children had normal white/pink nails while all the rest had pale nails (Figure 9). Spotted nails show zinc, calcium, protein deficiency, fungal infections and indication of hepatic or renal disease. Spooned nails show iron deficiency anaemia. And pale nails show calcium, iron and protein deficiency, and also an indicator of jaundice related to hepatobiliary disease [19].

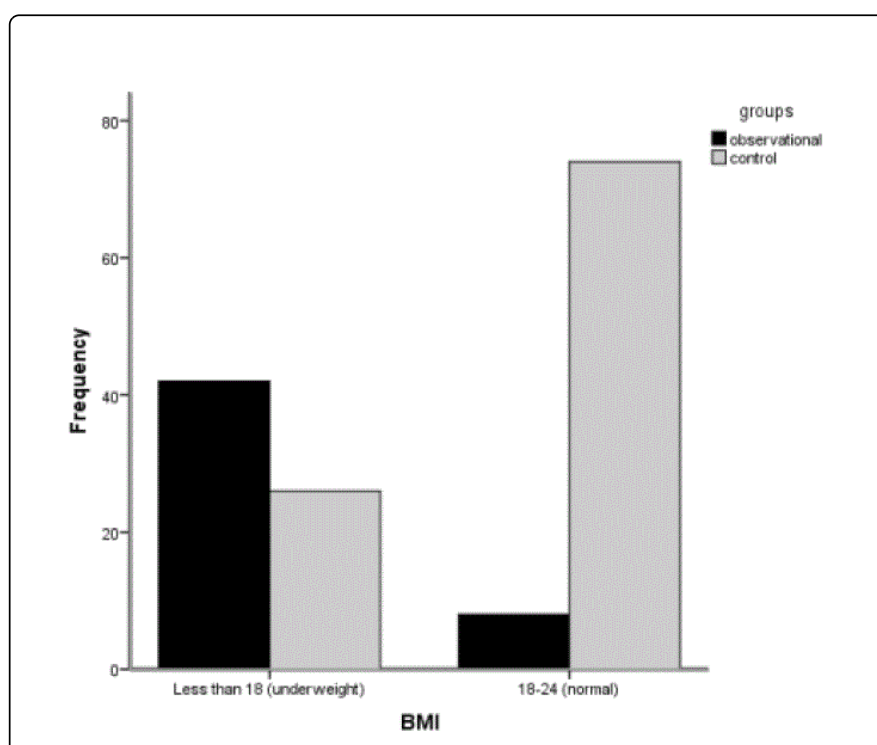

Figure 7: Line graph showing Body-Mass-Index $\left(\mathrm{Kg} / \mathrm{m}^{2}\right)$ of participants in both groups.

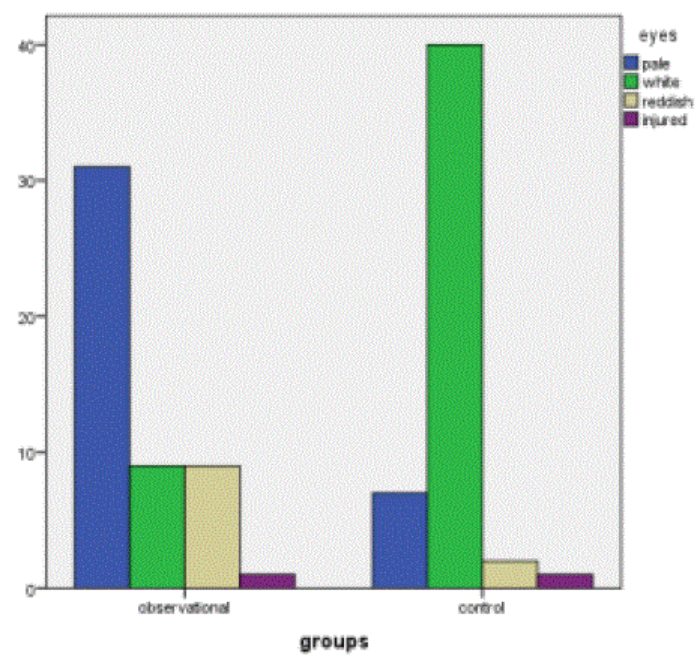

Figure 8: Bar diagram showing results of clinical symptoms for eyes. 


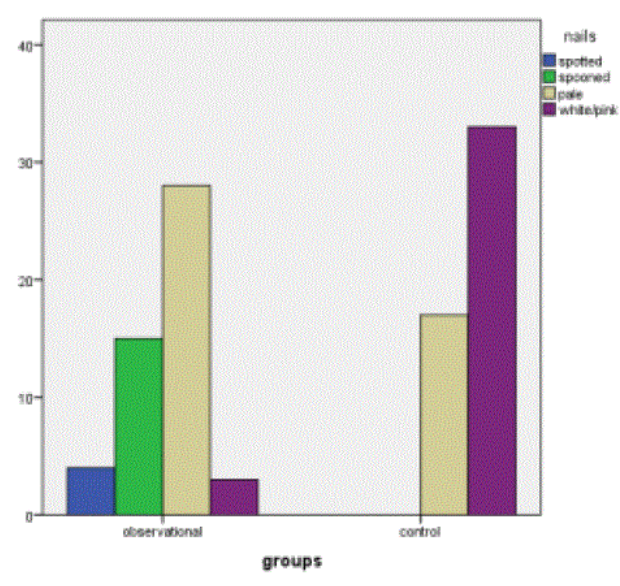

Figure 9: Bar diagram showing results of clinical symptoms for nails.

Teeth: In group A, about 36\% children were having cavities, $30 \%$ discoloured teeth, and $30 \%$ normal teeth. Contrary to this, in group B, $78 \%$ had normal teeth. Also the frequency of broken teeth was higher group A than group B (Figure 10). These results indicate that wasteexposed children had bad eating habits and improper oral hygiene practices [20].

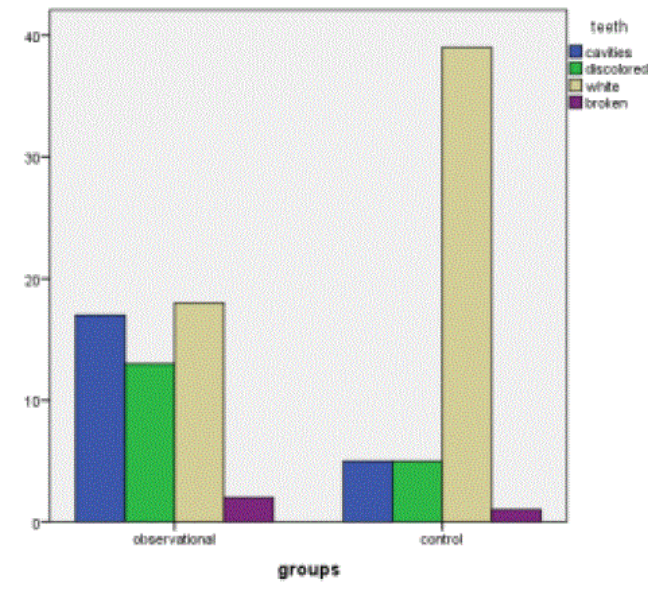

Figure 10: Bar diagram showing results of clinical symptoms for teeth.

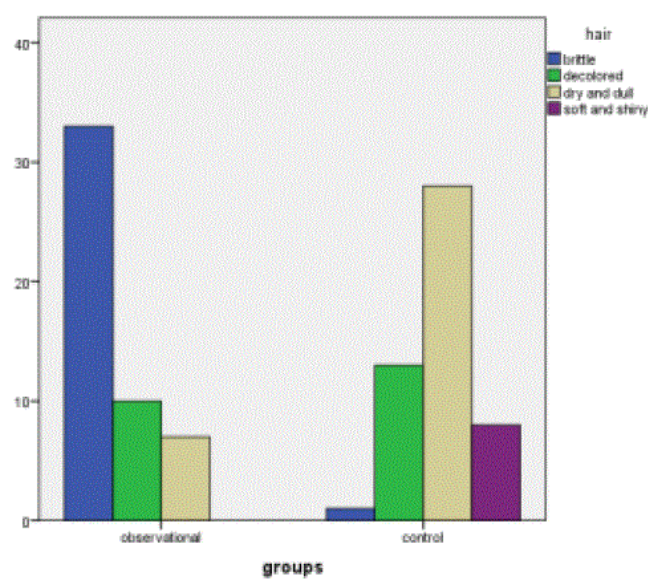

Figure 11: Bar diagram showing results of clinical symptoms for hair.

Hair: About 70\% group A had brittle hair, almost all had decoloured hair and not a single one had normal soft hair. On the other hand, about $60 \%$ group B children had dry and dull hair, and $20 \%$ normal, soft and shining hair (Figure 11). Brittle hair are the indicator of zinc, iron and vitamin $\mathrm{C}$ deficiencies, while dull and dry hair shows iron, folate, vitamin B1 and B3, and protein deficiencies [21]. Decoloured hair exhibit environmental hazardous affects including exposure to sulphur oxides (SOx), nitrogen oxides (NOx), persistent organic pollutants (POPs), ultraviolet radiations in sunlight and ozone fragments in air [22].

Skin: About 35\% hyperpigmentation was observed in both groups. Hyper-pigmentation due to abnormal melanin production is a result of oxidative damage in skin on exposure to ultraviolet sun rays and hazardous air pollutants. This situation can be indirectly ceased or avoided by having diet rich in fruit polyphenols which are exogenous antioxidant sources [23]. About $60 \%$ waste-exposed children had pale skin, and were more likely to have nutritional deficiencies like iron deficiency anaemia, vitamin $\mathrm{A}$, vitamin $\mathrm{C}$ and zinc deficiency. Rest of the sample had dry skins and only $8 \%$ existence of normal skin was found in waste-unexposed children (Figure 12). 
Citation: Awan R, Khan N, Nasir M (2016) Impact of Domestic Waste Exposure on Health and Nutritional Status of Children Aged 5-7 Years. Vitam Miner 5: 148.

Page 6 of 9

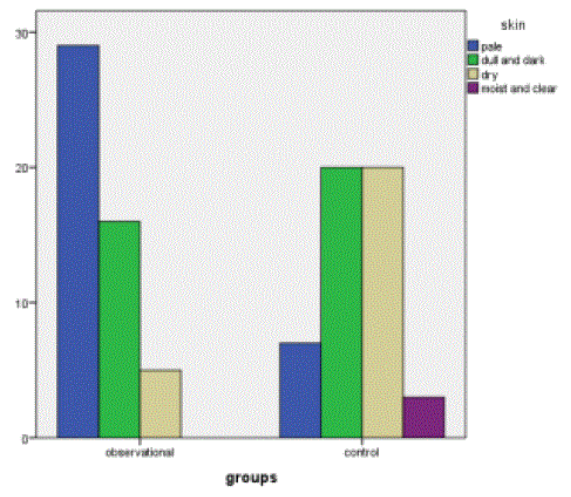

Figure 12: Bar diagram showing results of clinical symptoms for skin.

Health History: Health history results include stool pattern and character, prevalence of infections and allergies, and frequent diseased status among children. Surprisingly, the results for disease status were almost similar for both group (Figure 13), 'very often' was the most prevalent outcome. It can be reasoned as the likelihood of getting sick in waste-exposed group was ultimately cut down due to their permanent unhealthy physical conditions and a set point body defence system approach to them. Likewise, in waste-unexposed children, immunity is poorly developed due to their weaker physical structures as a result of poor nutrition and health conditions, as per belonging to low socio-economic status.

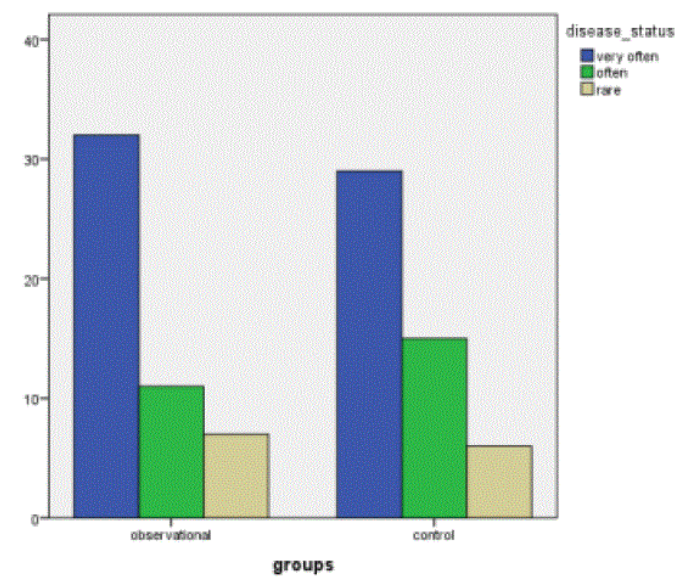

Figure 13: Bar diagram showing results for disease status in both groups.

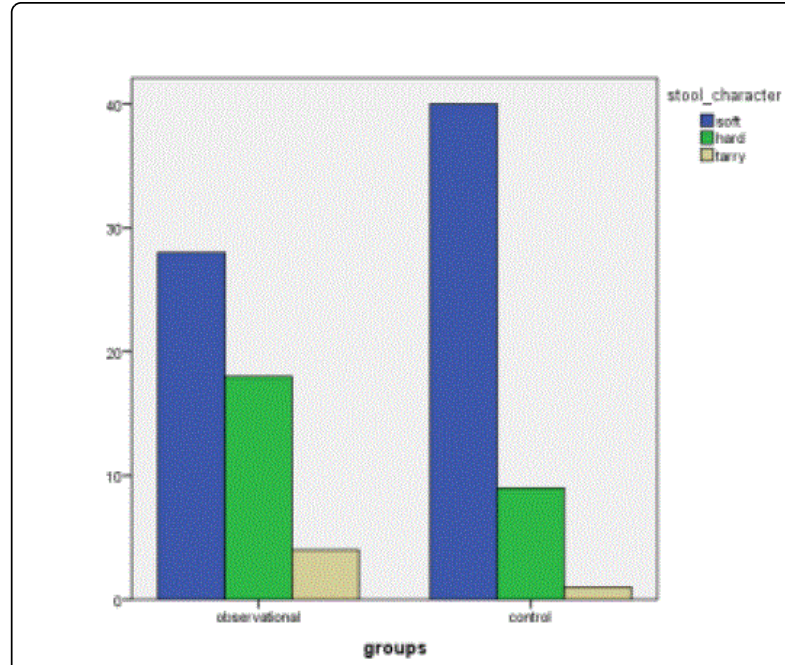

Figure 14: Bar diagram showing results for stool character of both groups.

Stool Analysis: The stool character was observed for soft (normal), hard (constipated) and tarry (gastrointestinal bleeding and malabsorption) forms. It was determined that most of the wasteexposed children had tarry stool while waste-unexposed children had soft and hard stool (Figure 14). According to the results of stool pattern analysis, the waste-exposed children were more at risk of diarrhea, and least at risk of constipation, while waste-unexposed children had normal stool pattern with least risk of diarrhea (Figure 15). Unhygienic food handling and cooking condition together with the continuous exposure to hazardous air pollutants was a cause of gastrointestinal disorders of malabsorption and ulceration among group A.

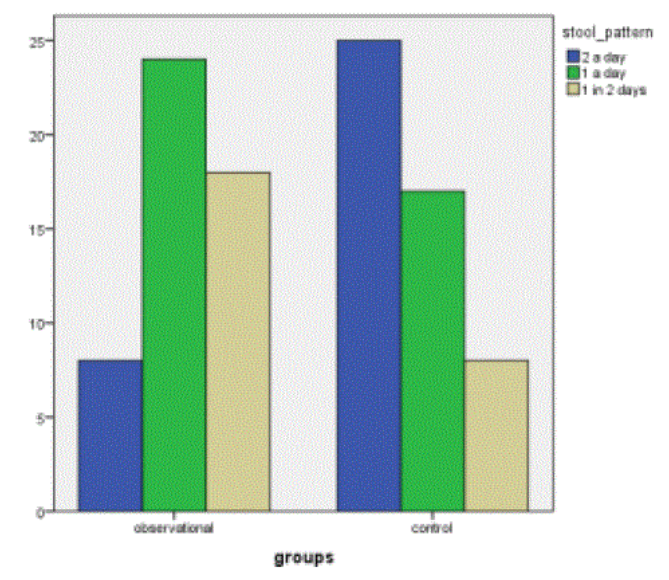

Figure 15: Bar diagram showing results for stool pattern of both groups.

Infections and allergies: in group A, skin infections (dermatitis) and allergies were the most common health problem. The pathogenic microbial contaminated land, water and air leads to numerous bacterial, viral, fungal and protozoan infections to skin being majorly exposed to them. Chemical hazards that cause serious skin ailments 
Citation: Awan R, Khan N, Nasir M (2016) Impact of Domestic Waste Exposure on Health and Nutritional Status of Children Aged 5-7 Years. Vitam Miner 5: 148.

Page 7 of 9

comprise of heavy metals poisoning, aldehydes, phenols and certain acids. Nervous disorders were also present in waste exposed children, as open-waste dumping has an impact over the nervous system causing neurological and psychological disorders. The main observations for eye infections were redness, sores, swelling, poor vision and eye centering disorders among waste-exposed children (Figure 16).

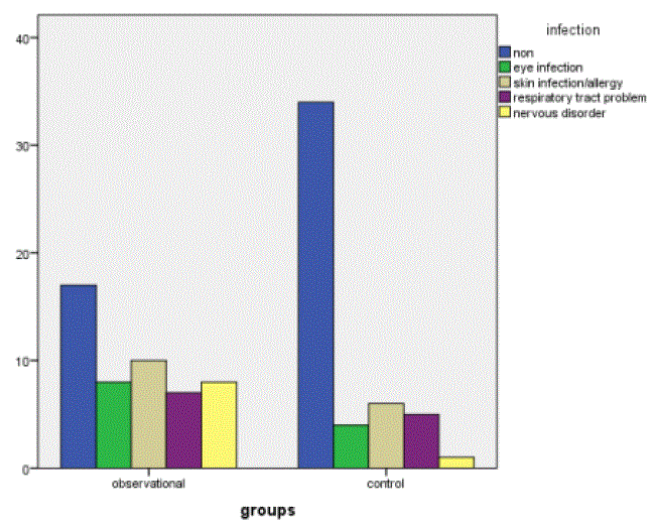

Figure 16: Bar diagram showing presence of different infections in both groups.

\section{CDC growth charts analyses}

Weight-for-Age percentile growth chart: There existed a significant difference between the scores of both groups i.e., group A scored in lower ranges of $3^{\text {rd }}-5^{\text {th }}$ percentile showing the prevalence of wasting however group B scored in higher ranges of $75^{\text {th }}-95^{\text {th }}$ percentile showing healthy weight regarding to their ages i.e., $t(99)=-13.45$ $(\mathrm{p}=0.000)$ (Figure 17).

Height-for-Age Percentile Growth Chart: For both groups, heightfor age percentile scores peaked in the same range but higher percentile scores were occupied by lesser group A subjects as compared to group B ones. These results of height-for-age percentile growth charts stated no significance difference among groups i.e., $t(99)=-1.48$ $(\mathrm{p}=0.139)$. It can be justified by the fact that previous researches prove that stunting is the least parameter to observe nutritional status as it is influenced by several confounding factors like genetics, geographical surroundings, cast and race etc. Although, in the light of observed results, it can be said that stunting trend was more prominent among waste-exposed children (Figure 18).

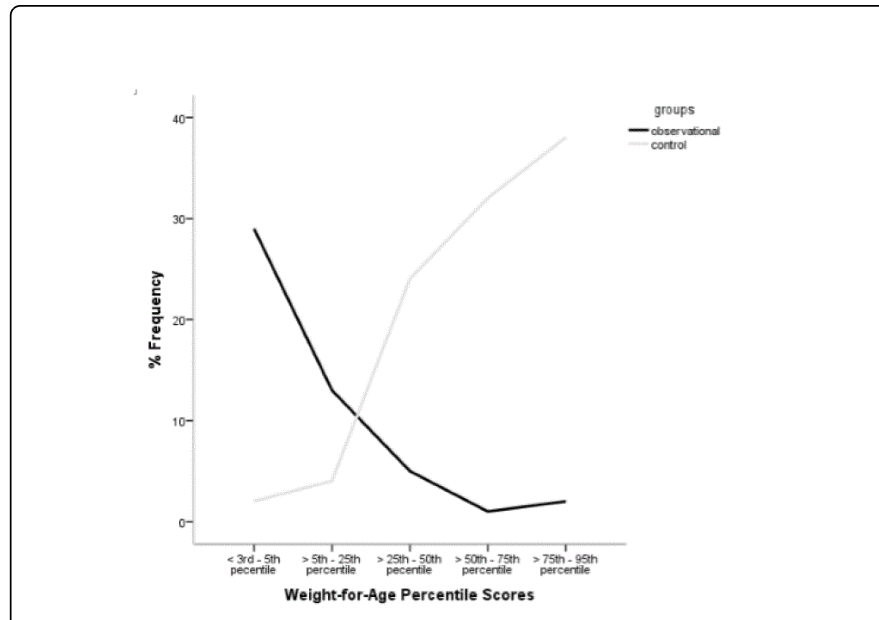

Figure 17: Line graph showing weight-for-age percentile scores for both groups.

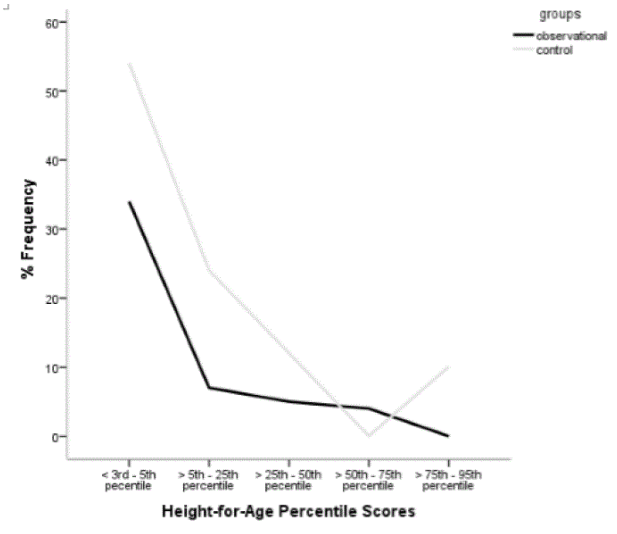

Figure 18: Line graph showing height-for-age percentile scores for both groups.

BMI-for-Age Percentile Growth Chart: A significant difference between the scores of both groups was observed i.e., $t(99)=-11.1$ $(\mathrm{p}=0.000)$. The group A scored in lower ranges of $5^{\text {th }}-50^{\text {th }}$ percentile showing the prevalence of underweight while group B scored in higher ranges of $85^{\text {th }}-95^{\text {th }}$ percentile showing normal and even overweight BMI according to their ages (Figure 19). 


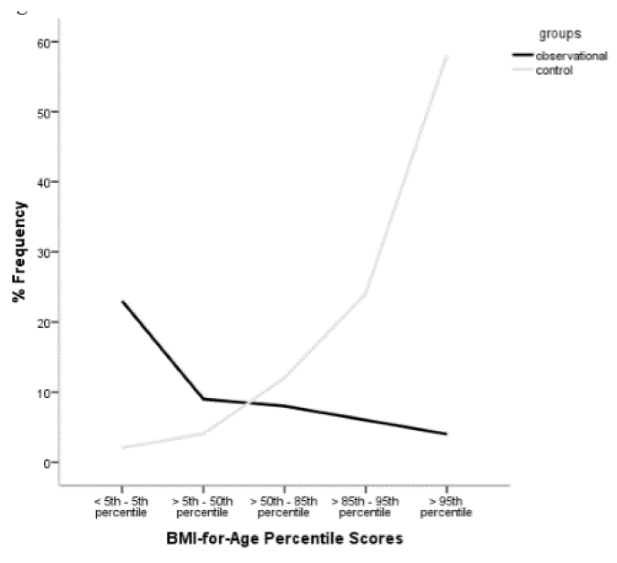

Figure 19: Line graph showing BMI-for-age percentile scores for both groups.

The overall nutritional status of group A was considered as unsatisfactory with $76 \%$ children scoring average or below average scores. Although the incidence of satisfactory nutritional status was also lower than unsatisfactory among group B, but the ratio was comparatively higher as compared to waste-exposed group i.e., 0.31 for waste-exposed children and 0.72 for waste-unexposed children (Figure 20).

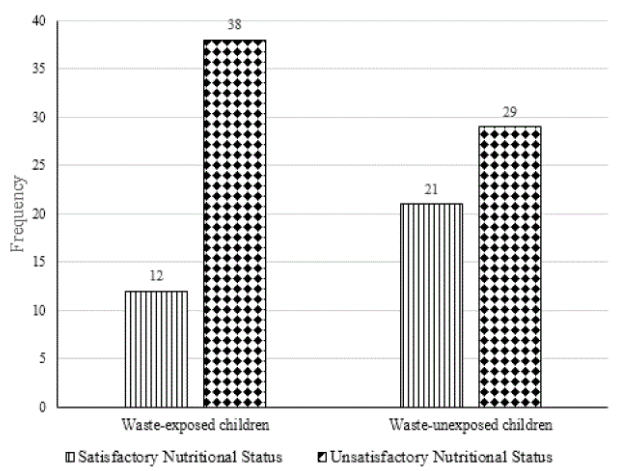

Figure 20: Bar diagram showing nutritional status outcomes based upon growth charts interpretation.

\section{Residential conditions at slums}

Slums comprised of huts made of cloths, polyethene sheets and bamboo sticks. Such residential conditions are more susceptible to harsh climate, polluted environment, biological hazards and communicable diseases. The ground was fully covered with filth and garbage. The household fuel requirement was taken care of by burning bags made of paper, plastic-components and foils which spread toxic pollutants in the air. Water supply was three miles far from slums which comprised of dirty water taps provided by municipal authorities of the area. Overall, the residential conditions of group A were the major cause of their compromised health and nutritional status.
While summarizing all results, the main observations revealed that the weight, height and BMI was found relatively low in waste-exposed children. Clinical symptoms of iron, calcium and protein deficiencies were identified in waste-exposed children by pale eyes, nails and skin and discolored teeth and brittle hair. Overall disease status in both groups was almost similar. The stool character of waste-exposed children was tarry and more liquorish, and diarrhea was anticipated by stool pattern. Moreover, a wide range of infections were found in waste-exposed children. These problems included eyes infection, skin infections/allergies, respiratory tract infections and nervous disorders. As far as the results of CDC percentile growth charts were concerned, the observational group scored lower than control group for weightfor-age and BMI-for-age growth charts, whereas for height-for-age growth charts the results were not clearly distinct. Hence, it has been proved that waste exposure damages children's health and nutritional status.

\section{Acknowledgements}

The authors thank Kalsoom Akhtar for statistical guidance, and Hafiz Suleman Awan for site photography. The present study was selffunded by the researchers. The authors' contributions were as follows: R.A. developed and tested data form, collected and analysed data, and wrote manuscript. N.K. participated in defining sample and writing manuscript. M.N.K. contributed in study design. All authors read and approved the final version of manuscript. The authors have no financial or personal conflicts of interest to declare.

\section{References}

1. UNEP (2016) Human health and environment. United Nations Environment Programs.

2. Gouveia N, Pardo RR (2010) Health risks in areas close to urban solid waste landfill sites. Rev Saúde Pública 44: 1-8.

3. Kimani NG (2012) Environmental pollution and impacts on public health: implications of the Dandora unicipal dumping site in Nairobi, Kenya. Urban Environment Unit - United Nations Environment Programs.

4. Mbengue R, Thiam MD, Traore VB (2015) Impacts of household solid urban waste on the coast of Ngor (Dakar/Senegal). Eur J Ear Env 2: 15-29.

5. Ocampo CE, Epidemiol MD, Pardilla A (2008) Impact of waste disposal site on children physical growth. Colombia Médica 39: 253-259.

6. Paigen B, Goldman LR, Magnant MM (1987) Growth of children living near the hazardous waste site, Love Canal. Human Biology 59: 489-508.

7. Vrijheid M (2000) Health effects of residence near hazardous waste landfill sites: a review of epidemiologic literature. Environ Health Perspect 108: 101-112.

8. Lassmann HA (2016) Children with physical disability in the child welfare system: the influence of a co-occurring diagnosis. Society for Social Work and Research.

9. Barell V, Aharonson-Daniel L, Fingerhut LA (2002) An introduction to the Barell body region by nature of injury diagnosis matrix. Injury Prevention: Journal of International Society for Child and Adolescent Injury Prevention 8: 91-96.

10. Knox TA, Zafonte-Sanders M, Moen K (2003) Assessment of nutritional status, body composition, and human immunodeficiency virus-associated morphologic changes. Clinical Infectious Disease: An official publication of the Infectious Disease Society of America 36: S63-S68.

11. Srivastava A, Mahmood SE, Shrotriya VP (2012) Nutritional status of school-age children-a scenario of urban slums in India. Achieves of Public Health: Journal of Belgian Public Health Association 70: 1.

12. Kundu N (2003) The case of Kolkata, India. Case Studies on Global Reports on Human Settlements. 
Citation: Awan R, Khan N, Nasir M (2016) Impact of Domestic Waste Exposure on Health and Nutritional Status of Children Aged 5-7 Years. Vitam Miner 5: 148.

Page 9 of 9

13. Javadekar N (2013) Literacy and poverty related issues in India. India Times.

14. Ahmed G, Faiz D, Sultan R (2015) An overview of the illiteracy and underlying causes in Pakistan. J Econ Entomol 33: 213-217.

15. Rathor A (2013) Slum dwellers, curse on development. 2nd edn. Sarup and Sons Publishers, New Delhi, India.

16. Brown JE, Isaacs J, Lechtenberg E (2014) Nutrition Through the Lifecycle. 5th edn. Belmont, CA: Wadsworth, USA.

17. Fleming A, Gram D, Bowmann F (2015) Nutritional deficiencie indicators in children and their reliabilities. Int J Pediatr 231: 2134-2140.

18. Massignan C, Cardoso M, Porporatti A (2016) Signs and symptoms of primary tooth eruption - a meta-analysis. Paediatrics 137: 1-19.

19. Xiaolong Z, Sikandar G, Tamura D (2010) Brittle hair, developmental delay, neurological abnormalities and photosensitivity in a 4 years old girl. J Am Acad Dermatol 63: 323-328.
20. Christopher J, Randall J, Gillman J (2016) Natural environments and chronic stress measured by hair cortisol. Landsc Urban Plan 148: 61-67.

21. Hsieh TF, Chang YN, Liu BL (2015) Effect of extracts of Chinese medicines on anti-tyrosinase and antioxidant activities. J Med Plant Res 48: 1131-1138.

22. CDC (2016) Skin exposures and effects. National Institute of Occupational Safety and Health. Centers for Disease Control and Prevention.

23. Marshall EG, Gensburg LJ, Deres DA (2015) Maternal residential exposure to hazardous wastes and risk of central nervous system and musculoskeletal birth defects. Arch Environ Health 70: 416-425. 